Check for updates

Cite this: Chem. Sci., 2018, 9, 7822

๑ All publication charges for this article have been paid for by the Royal Society of Chemistry

Received 29th June 2018

Accepted 6th August 2018

DOI: $10.1039 / \mathrm{c} 8 \mathrm{sc} 02875 \mathrm{c}$

rsc.li/chemical-science

\section{Phosphorescent cationic iridium(III) complexes dynamically bound to cyclodextrin vesicles: applications in live cell imaging $\dagger$}

\author{
Frauke Schibilla, ${ }^{a}$ Anna Holthenrich, ${ }^{\mathrm{b}}$ Boyi Song, ${ }^{\mathrm{c}}$ Anna Livia Linard Matos, ${ }^{\mathrm{b}}$ \\ David Grill, ${ }^{\mathrm{b}}$ Diego Rota Martir, ${ }^{\mathrm{c}}$ Volker Gerke, ${ }^{\mathrm{b}}$ Eli Zysman-Colman (iD) *c \\ and Bart Jan Ravoo (D)*a
}

\begin{abstract}
We report cationic $\operatorname{Ir}($ III) complexes functionalized with adamantyl groups designed to bind to $\beta$ cyclodextrin vesicles (CDV) with high affinity $\left(K_{a}=1 \times 10^{6} \mathrm{M}^{-1}\right)$. The emission of the complexes is tuned by changing the nature of the cyclometalating ligands. The host-guest adduct of CDV and Ir(III) complexes shows increased and significantly blue-shifted emission due to the lower mobility of the Ir(III)complexes residing in the less polar environment of the vesicle surface. Ir(III)-decorated CDV are efficiently taken up by cells and can be used in live cell imaging. The CDV act as carriers to transport the phosphorescent complexes into cells where they selectively stain mitochondria.
\end{abstract}

\section{Introduction}

Cationic $\operatorname{Ir}(\mathrm{III})$ complexes containing two bidentate cyclometalating ligands $\left(\mathrm{C}^{\wedge} \mathrm{N}\right.$, e.g., 2-phenylpyridinato, ppy) and one bidentate diimine ligand $\left(\mathrm{N}^{\wedge} \mathrm{N}\right.$, e.g., 2-2'-bipyridine, bpy) are a family of phosphorescent materials featuring microsecond emission lifetimes $\left(\tau_{\mathrm{PL}}\right)$, high photoluminescence quantum yields $\left(\Phi_{\mathrm{PL}}\right)$, wide color tunability as a function of ligand design, and high photo- and chemostability. ${ }^{1,2}$ Cationic Ir(III) complexes are widely used in organic light-emitting diodes (OLEDs), ${ }^{3-5}$ chemosensing systems ${ }^{6-8}$ and bioimaging..$^{9-11}$ Bioimaging, in particular the visualization of specific processes and structures in live biological specimens such as cells, has greatly benefitted from the introduction of fluorescence-based imaging methods together with tools to deliver such fluorescence probes into cells. Luminophores used in live cell imaging should exhibit high chemoselectively, biocompatibility and optical brightness. ${ }^{12}$ Cationic $\operatorname{Ir}($ III)-complexes are attractive candidates for

${ }^{a}$ Organic Chemistry Institute and Center for Soft Nanoscience, Westfälische Wilhelms-Universität Münster, Correnstrasse 40, 48149 Münster, Germany. E-mail: b.j.ravoo@uni-muenster.de

${ }^{b}$ Institute of Medical Biochemistry, Center for Molecular Biology of Inflammation, Cells-in-Motion Cluster of Excellence (EXC1003-CiM), Westfälische WilhelmsUniversität Münster, Von-Esmarch-Strasse 56, 48149 Münster, Germany

'Organic Semiconductor Centre, EaStCHEM School of Chemistry, University of St Andrews, St. Andrews, Fife KY16 9ST, UK. E-mail: eli.zysman-colman@st-andrews. ac.uk

$\dagger$ Electronic supplementary information (ESI) available: Experimental procedures, absorption and emission spectra, isothermal titration calorimetry, cell culture experiments and synthesis. See DOI: $10.1039 / \mathrm{c} 8 \mathrm{sc} 02875 \mathrm{c}$. The research data supporting this publication can be accessed at https://doi.org/10.17630/1254db92-71d2-45a6-ac87-247894110d66. bioimaging, showing several advantages over organic fluorophores, due to their outstanding photophysical properties, including high $\Phi_{\mathrm{PL}}$, photobleaching resistance due to both the long $\tau_{\mathrm{PL}}$ and large Stokes shifts. ${ }^{13-16} \operatorname{Ir}(\mathrm{III})$-alkyne probes, for example, were utilized for real-time imaging of dynamic processes in live cells by photoluminescence lifetime imaging. ${ }^{17}$ The cytotoxicity and solubility of probes are two major concerns for biological applications. One strategy to enhance the potential of cyclometalated $\operatorname{Ir}(\mathrm{III})$ complexes as imaging (re)agents and cellular probes is to couple a poly(ethylene glycol) (PEG) chain resulting in good solubility and low cytotoxicity. ${ }^{18-20}$ For the purpose of photodynamic therapy a high cytotoxic activity can be useful, but for cellular probes minimal cytotoxicity is desired. ${ }^{21}$

Cyclodextrins (CD) are well known to form host-guest inclusion complexes with hydrophobic guest molecules, ${ }^{22-24}$ which are for example used for cell surface functionalisation ${ }^{25}$ or as nanocarriers. ${ }^{26}$ Amphiphilic CD derivatives self-assemble in aqueous solution to form CD vesicles (CDV). ${ }^{27} \mathrm{CDV}$ are biocompatible and have, for example, been used as a model for biological cell membranes. ${ }^{28}$ The cavity of the CD in the CDV remains available for host-guest interactions. Thus, the surface of the CDV can be decorated by various functionalities via molecular anchors such as adamantane. These interactions have been exploited towards a "self-assembled glycocalyx" ${ }^{29,30}$ by decorating CDV with carbohydrates. Moreover, decoration of CDV with stimulus-responsive polymer shells resulted in nanocontainers that could be applied for triggered payload delivery into cells. ${ }^{31}$ However, CDV without polymer shells have never been used to deliver compounds into cells and CDV have never been functionalized with $\operatorname{Ir}(\mathrm{III})$ complexes.

There are but a small number of studies that combine phosphorescent complexes with CDs. ${ }^{32}$ Yam et al. immobilized 


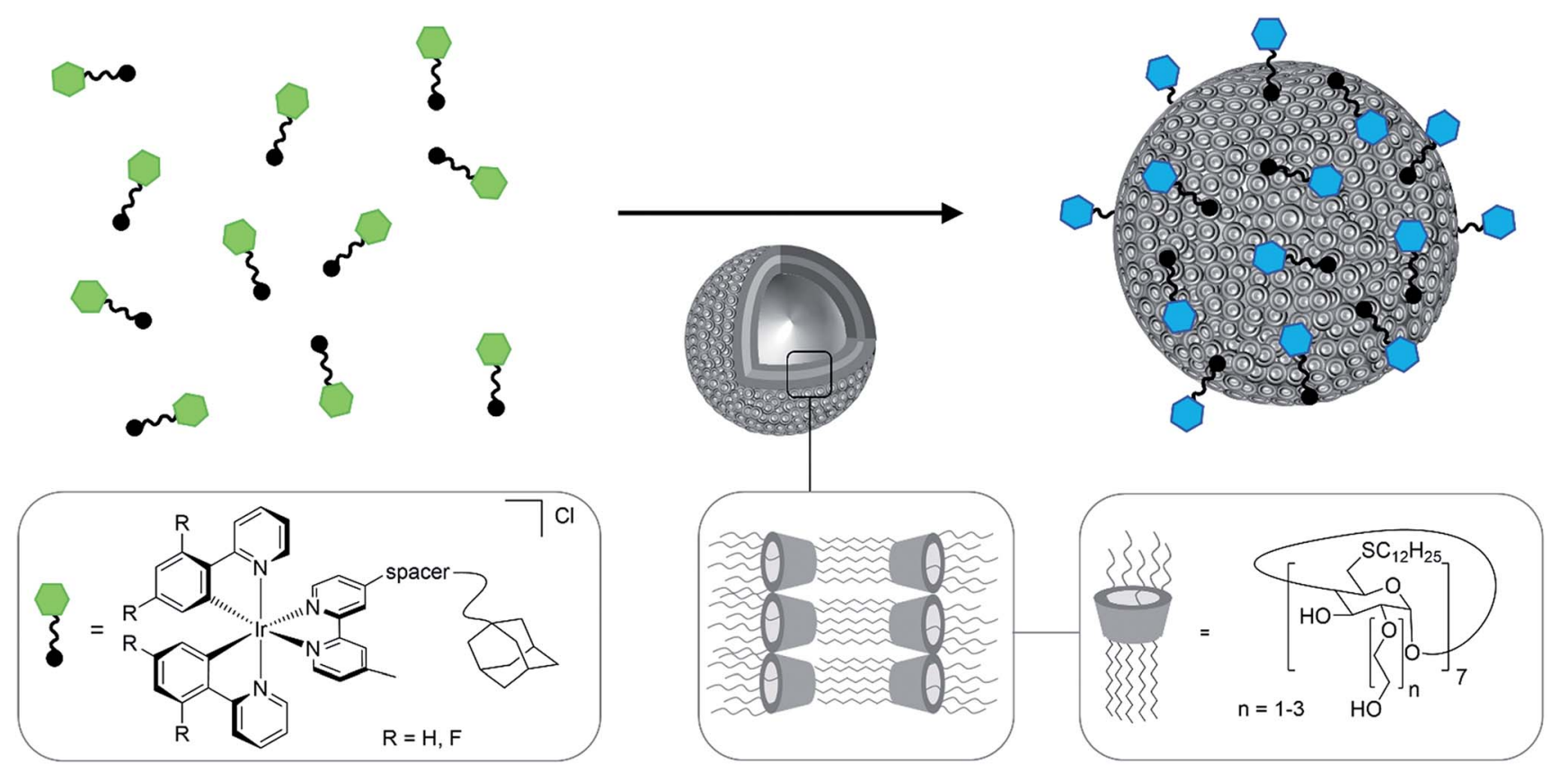

Fig. 1 Schematic representation of the formation of luminescent vesicles by host-guest interaction of CDV and Ir(III) complexes. The green and blue color represent the blue shift of the emission upon the immobilization of the Ir(III) complexes on the CDV.

adamantane-functionalized $\mathrm{Ru}(\mathrm{II})$ and $\mathrm{Re}(\mathrm{I})$ complexes on $\beta$-CD capped gold nanoparticles for the detection of biomolecules. ${ }^{33}$ Furthermore, a three component system consisting of a CD substituted Ir-complex as the photosensitizer, a viologen-based electron relay and CD-modified platinum nanoparticles as the catalyst was developed for the generation of hydrogen. ${ }^{34,35}$

In this study, five water-soluble cationic Ir-complexes, four of which are functionalized with adamantyl units that can form host-guest assemblies with CDV, were generated and analyzed. The emission properties of the Ir-luminophores were tuned by using either 2-phenylpyridine (ppyH) or 2-(2,4-difluorophenyl) pyridine $(\mathrm{dFppyH})$ as the cyclometalating ligands. The ancillary ligand constituted of a 2,2'-bipyridine (bpy) functionalized with either one or two tetraethylene glycol chains bearing a terminal adamantyl group (Fig. 1). The tetraethylene glycol linker was used to improve the water solubility, with the added benefit of lowering cytotoxicity. The Ir-decorated CDV were applied as luminescent probes in live cell imaging experiments allowing the visualization of intracellular compartments.

\section{Results and discussion}

The investigated adamantane-functionalized Ir(III)-complexes 1a, 1b (one adamantane substituent), $\mathbf{2 a}$ and $\mathbf{2 b}$ (two adamantane substituents) and reference compound $\left[\operatorname{Ir}(\mathrm{ppy})_{2}(\mathrm{bpy})\right]$ $\mathrm{Cl}, 3$, are shown in Fig. 2. The synthesis is described in the ESI. ${ }^{\dagger}$

\section{Photophysical characterization}

The photophysical properties of the complexes were investigated by steady-state and time-resolved emission spectroscopy in both acetonitrile (MeCN) and phosphate buffer solutions,
$(\mathrm{PB} ; \mathrm{pH}=7.4)$. The photophysical properties of $\mathbf{1 a}$ and $\mathbf{1 b}$ are summarized in Table 1. All complexes mainly absorb in the UV region up to $c a$. $480 \mathrm{~nm}$ in both $\mathrm{MeCN}$ and $\mathrm{PB}$, with the fluorinated complexes (1) and $\mathbf{2 b}$ ) showing a significant shoulder at around $300 \mathrm{~nm}$ (ESI, Fig. S1†). The high energy absorption bands above $300 \mathrm{~nm}$ can be assigned to spin-allowed $\pi-\pi^{*}$ (ligand-centered, LC) transitions while bands between $300 \mathrm{~nm}$ and $425 \mathrm{~nm}$ are associated with mixed of spin-allowed metal-toligand charge-transfer $\left({ }^{1} \mathrm{MLCT}\right)$ and ligand-to-ligand charge-

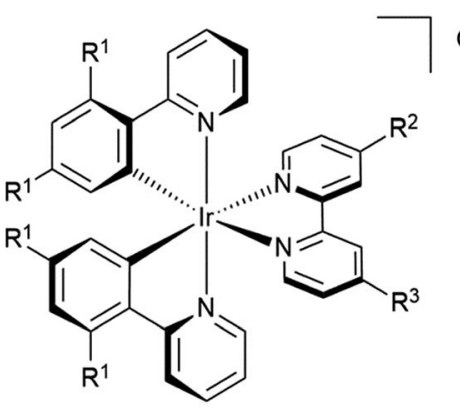

$$
\begin{gathered}
\mathrm{R}_{1}=H, \mathrm{R}_{2}=M e, \mathrm{R}_{3}=\text { AdL: } \mathbf{1 a} \\
\mathrm{R}_{1}=\mathrm{F}, \mathrm{R}_{2}=M e, \mathrm{R}_{3}=\text { AdL: } \mathbf{1 b} \\
\mathrm{R}_{1}=H, \mathrm{R}_{2}=\mathrm{R}_{3}=\text { AdL: } \mathbf{2 a} \\
\mathrm{R}_{1}=\mathrm{F}, \mathrm{R}_{2}=\mathrm{R}_{3}=A d L: \mathbf{2 b} \\
\mathrm{R}_{1}=\mathrm{R}_{2}=\mathrm{R}_{3}=\mathrm{H}: \mathbf{3}
\end{gathered}
$$

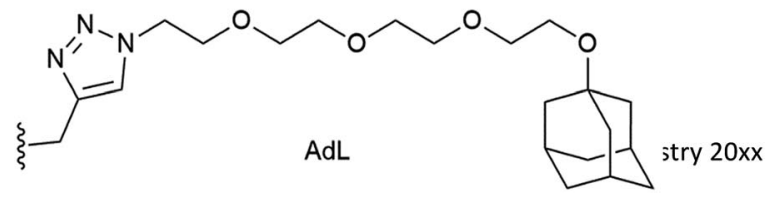

Fig. 2 Molecular structure of Ir(III) complexes $1 a, 1 b, 2 a, 2 b$ and 3. 
Table 1 Photophysical data of $1 \mathrm{a}$ and $1 \mathrm{~b}$ in degassed (deg.) $\mathrm{MeCN}$, deg. PB and PB (air)

\begin{tabular}{llcl}
\hline Entry & $\lambda_{\mathrm{PL}}{ }^{a}[\mathrm{~nm}]$ & $\Phi_{\mathrm{PL}}[\%]$ & $\tau_{\mathrm{PL}}{ }^{d}[\mathrm{~ns}]$ \\
\hline 1a, deg. MeCN & 557 & $34.6^{b}$ & 475 \\
1a, deg. PB & 565 & $3.8^{b}$ & 74 \\
1a, PB (air) & 565 & $3.5^{b}$ & 73 \\
1b, deg. MeCN & 520 & $62.8^{c}$ & 1310 \\
1b, deg. PB & 525 & $34.2^{c}$ & 791 \\
1b, PB (air) & 525 & $14.8^{c}$ & 459
\end{tabular}

${ }^{a} \lambda_{\text {exc }}=360 \mathrm{~nm} .{ }^{b} \lambda_{\text {exc }}=420 \mathrm{~nm}$, using $\left[\mathrm{Ru}(\mathrm{bpy})_{3}\right] \mathrm{Cl}_{2}$ as the standard $\left(\Phi_{\mathrm{PL}}=4 \%\right.$ in aerated $\mathrm{H}_{2} \mathrm{O}$ at $\left.298 \mathrm{~K}\right) .^{38}{ }^{3} \lambda_{\text {exc }}=360 \mathrm{~nm}$, using quinine sulfate as the standard $\left(\Phi_{\mathrm{PL}}=54.6 \%\right.$ in $0.5 \mathrm{M} \mathrm{H}_{2} \mathrm{SO}_{4}$ at $\left.298 \mathrm{~K}\right){ }^{39} d \lambda_{\text {exc }}$ $=378 \mathrm{~nm}$.

transfer $\left({ }^{1}\right.$ LLCT) transitions. ${ }^{36}$ Complexes 1a, 2a, and 3 each show broad and unstructured orange emission in PB with an emission maximum at $565 \mathrm{~nm}$. The presence of the triazoletetraethylene glycol chains on the ancillary ligand has little effect on the optoelectronics of the complex. Complexes $\mathbf{1} \mathbf{b}$ and 2b show significantly more intense, broad and unstructured green emission at $525 \mathrm{~nm}$ in PB (ESI, Fig. S1†), which is the result of the inclusion of the electron-withdrawing fluorine atoms on the cyclometalating ligands. ${ }^{37}$

Photoluminescence lifetimes, $\tau_{\mathrm{PL}}$, and photoluminescence quantum yields, $\Phi_{\mathrm{PL}}$, of $\mathbf{1 a}$ and $\mathbf{1 b}$ were measured in degassed MeCN, degassed PB, and PB in air. In MeCN, 1a exhibited a $\tau_{\mathrm{PL}}$ of 475 ns with a $\Phi_{\mathrm{PL}}$ of $35 \%$. For $\mathbf{1 b}$ the $\tau_{\mathrm{PL}}$ is considerable longer at $1310 \mathrm{~ns}$, along with a correspondingly higher $\Phi_{\mathrm{PL}}$ of $63 \%$. In general, both Ir-complexes $1 \mathrm{a}$ and $1 \mathrm{~b}$ show a blueshifted emission and a higher $\Phi_{\mathrm{PL}}$ compared to literature complexes $\left[\operatorname{Ir}\left(\right.\right.$ ppy)(bpy)] $\mathrm{PF}_{6}$ (ref. 40) or $[\operatorname{Ir}(\mathrm{dFppy})(\mathrm{bpy})] \mathrm{PF}_{6}{ }^{{ }^{\mathbf{1 1}}}$ respectively. The emission was significantly quenched in aqueous solution, which was previously observed for other Ircomplexes. ${ }^{42-44}$ In PB the photophysical properties of 1a did not show any sensitivity to $\mathrm{O}_{2}(\sim 73 \mathrm{~ns}, 4 \%$, with and without air). On the other hand, $\mathbf{1 b}$ did show oxygen sensitivity, with considerable quenching of both the $\tau_{\mathrm{PL}}$ and the $\Phi_{\mathrm{PL}}$ compared to degassed conditions (791 ns, 34\% to $459 \mathrm{~ns}, 15 \%$ ).

\section{Interaction with cyclodextrin vesicles}

The interaction of $\mathbf{1 a}$ and $\mathbf{1 b}$ with $\beta$-CD was investigated by isothermal titration calorimetry (ITC). Both show a $1: 1$ stoichiometry and association constants of around $10^{4} \mathrm{M}^{-1}$, which are comparable to those reported for similar adamantane/ $\beta-\mathrm{CD}$ interactions. ${ }^{45}$ The association constant of the fluorinated complex $1 \mathrm{~b}\left(K_{\mathrm{a}}=5.8 \times 10^{3} \mathrm{M}^{-1}\right)$ is a little lower compared to the non-fluorinated analog $1 \mathrm{a}\left(K_{\mathrm{a}}=1.9 \times 10^{4} \mathrm{M}^{-1}\right.$, ESI, Fig. S7 $\left.\dagger\right)$. The addition of unmodified $\beta-\mathrm{CD}$ to $\mathbf{1 a}$ or $\mathbf{1 b}$ does not influence either the absorption or luminescence profiles of the Ir-complex (ESI, Fig. S2 $\dagger$ ).

The behavior of the Ir-complexes with CDV was subsequently investigated. The preparation of the CDV is described in the ESI. $\uparrow$ Titration of non-emissive CDV $(1-100 \mu \mathrm{M})$ into a constant concentration of Ir-complex $(10 \mu \mathrm{M})$ resulted in changes in both the emission intensity and profile (Fig. 3). Zeta-potential
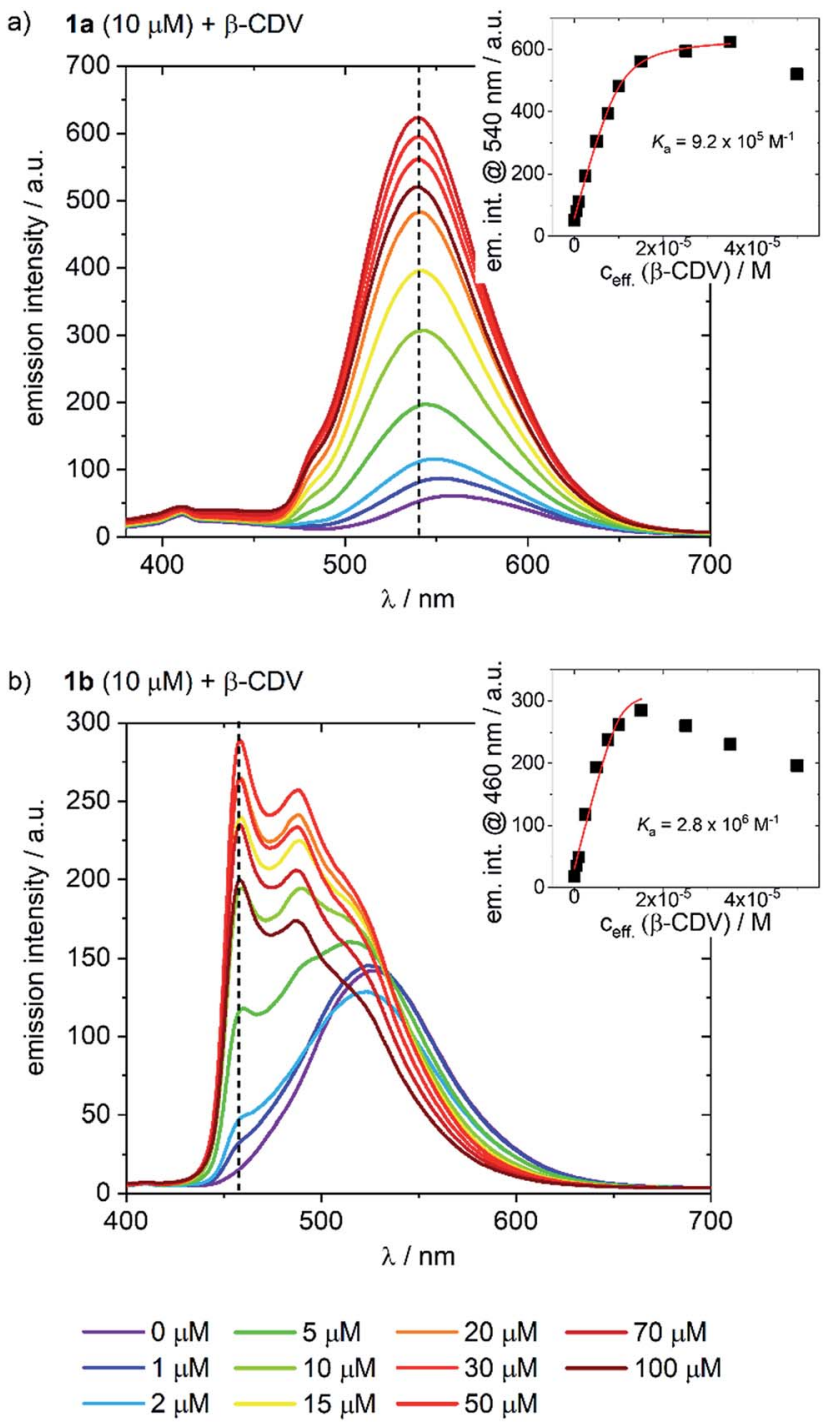

Fig. 3 Emission spectra of (a) $1 \mathrm{a}$ and (b) $1 \mathrm{~b}(10 \mu \mathrm{M})$ with increasing concentration of CDV $(0-100 \mu \mathrm{M})$ in PB; $\lambda_{\text {exc }}=360 \mathrm{~nm}$. The insets indicate the changes in emission intensity at (a) $540 \mathrm{~nm}$ and (b) $460 \mathrm{~nm}$ as a function of CDV concentration. Association constants $\left(K_{\mathrm{a}}\right)$ were calculated using a Langmuir regression. The effective concentration of CDV $\left(c_{\text {eff }}\right)$ is used because it is assumed that only CDs on the outer surface of the CDV are available for host-guest interaction.

measurements of the vesicles confirmed the expected hostguest interaction. Initially, CDV showed a slightly negative zetapotential of $c a$. $-6.5 \mathrm{mV}$, which became positive (up to $11 \mathrm{mV}$ ) upon association with the Ir-complexes (ESI, Table S1†). With high CDV to Ir-complex ratios $(\sim 5: 1)$, the potential is expectedly lower, due to lower coverage of the vesicles by the Ircomplex. This positive surface potential confirms an adhesion of the Ir-complexes to the surface of the vesicles.

The addition of CDV to a PB solution of 1a led to an increase in the emission intensity concomitant with a hypsochromic shift and a small shoulder appearing at $480 \mathrm{~nm}$ (Fig. 3a). At high CDV concentrations $(>70 \mu \mathrm{M})$ the emission intensity decreased. This is likely the result of aggregation-induced quenching, which was confirmed by DLS measurements and by scattering 
observed in the UV/vis spectra (ESI, Fig. S3/S8†). CDV were likewise added to $\mathbf{1 b}$ (Fig. 3b), resulting in a shift of the emission to higher energy. However, two sharp, non-shifting bands at 485 and $460 \mathrm{~nm}$ with increasing intensity were observed, which are the result of a change in the nature of the emission from ${ }^{3} \mathrm{CT}$ to ${ }^{3} \mathrm{LC}$. Association constants of $\mathbf{1 a}$ and $\mathbf{1 b}$ to CDV were calculated using a Langmuir regression of the fluorescence titrations (1a@CDV: $K_{\mathrm{a}}=9.2 \times 10^{5} \mathrm{M}^{-1}$; $1 \mathrm{~b} @ \beta-\mathrm{CDV}: K_{\mathrm{a}}=2.8 \times$ $10^{6} \mathrm{M}^{-1}$; Fig. 3, inset). The binding constants are around two orders of magnitude higher than for pure $\beta$-CD indicating high affinity binding to the CDV. We attribute the high binding constants to electrostatic interaction of the cationic Ir(III)complexes with the negatively charged surface of the CDV.

Most likely, the change in the nature of the emission, along with the blue shift, is a result of the less polar environment around the Ir-complexes when they are bound to the surface of the vesicles. Similar to 1a, at high CDV concentrations $(>30 \mu \mathrm{M})$ the emission intensity of $\mathbf{1 b}$ decreased, likely due to aggregation-induced quenching. The behavior of the complexes in the presence of CDV was investigated further. In PB, both 1a and $\mathbf{1 b}$ emit via a mixed CT state that was assigned based on a positive solvatochromic behavior (ESI, Fig. S4†); in apolar PhMe, the emission becomes structured and more ligandcentered, with maxima that align to those observed during the addition of CDV to the complexes.

To assess the contribution of the host-guest inclusion complexation of CDV and $\mathbf{1 a}$ or $\mathbf{1 b}$ to the observed changes in the emission spectra, we studied the addition of $\beta$-CDV to 3 , which acts as a negative control. A small increase in intensity and a blue-shift was observed, but these effects were negligible compared to those observed using 1a (ESI, Fig. S5 $\dagger$ ). Thus, the change in the emission properties observed for $\mathbf{1 a}$ and $\mathbf{1 b}$ can confidently be attributed to the host-guest interactions of the Ircomplexes with the CDV.

The emission lifetimes of the Ir-complexes were measured in the presence of CDV. In all cases the $\tau_{\mathrm{PL}}$ behavior was found to be bi-exponential, with a first component of a magnitude reminiscent of the Ir-complex without CDV (1a: 73 ns/1b: 459 $\mathrm{ns}$ ), and a second, longer component of around $530 \mathrm{~ns}$ for $\mathbf{1 a}$ and $1100 \mathrm{~ns}$ for $\mathbf{1 b}$, attributed to $\mathbf{1 a}$ and $\mathbf{1 b}$ bound to the CDV. This behavior may be explained by the dynamic nature of the host-guest system in which the Ir-complexes exist both as bound adducts and freely dissociated in solution. After degassing, the second lifetime component of $\mathbf{1 a}$ increased to around 630 ns while the first component stayed almost unchanged. In the case of $\mathbf{1 b}$, both lifetime components increased to around $500 \mathrm{~ns}$ and $1600 \mathrm{~ns}$, respectively.

The addition of a second adamantane unit onto the ancillary ligand in $\mathbf{2} \mathbf{a}$ and $\mathbf{2} \mathbf{b}$ was expected to increase the association constant of the $\mathbf{2 a} / \mathbf{2} \mathbf{b}-\mathrm{CDV}$ adduct through multivalency and thus increase the stability of the luminescent CDV while decreasing the amount of unbound Ir-complex in solution. To this end, the emission behavior of $\mathbf{2 a}$ and $\mathbf{2 b}$ with CDV was investigated. Both complexes demonstrated a behavior similar to $\mathbf{1 a}$ or $\mathbf{1 b}$, respectively, but aggregated at lower CDV concentrations (ESI, Fig. S6 $\dagger$ ), which can be explained by the undesired cross-linking of CDV through the Ir-complex.

\section{Cell experiments}

Ir-decorated CDV were applied as phosphorescent probes for live cell imaging, with the aim to develop a robust delivery system for imaging of intracellular compartments and trafficking. We selected complex $\mathbf{1 b}$ for cell experiments, because this complex showed a higher emission intensity compared to $1 \mathbf{a}$ in the in vitro studies. Human umbilical vein endothelial cells (HUVECs) were chosen as a model because they represent primary human cells. Toxicity and lytic activity of the Ircomplexes were analyzed by a cytotoxicity assay employing the compounds 1b, 1b in 1\% DMSO, 1b@CDV and only CDV at concentrations ranging from 0 to $100 \mu \mathrm{M}$ on HUVECs. Release of lactate dehydrogenase as an indicator of cell lysis was only observed at concentrations exceeding $80 \mu \mathrm{M}$ for CDV alone or 1b alone. Likewise, 1b@CDV showed relatively low cytotoxicity with significant cell lysing only observed at concentration above $15 \mu \mathrm{M}$. In contrast, $\mathbf{1 b}$ dissolved in 1\% DMSO was highly toxic inducing efficient cell lysis already at a concentration below 0.1 $\mu \mathrm{M}$ (ESI, Fig. S10†). Next, HUVECs were incubated with 1b@CDV or 3 and CDV and subjected to live cell imaging (Fig. 4). Efficient cellular uptake of the Ir-complex was dependent on the presence of the adamantane unit, since 3 and CDV showed very little intracellular luminescence signal (ESI, Fig. S11 $\dagger$ ). Although both $\mathbf{1 b}$ alone as well as $\mathbf{1 b} @ C D V$ were taken up and detected as elongated structures in the cell (ESI, Fig. S12 $\dagger$ ), 1b@CDV showed significantly higher intracellular fluorescence signals (Fig. 5). To gain insight about the fate of the CDV after internalization, we tried to visualize the CDV uptake by labeling the CDV with rhodamine. After addition of 1b@CDV-rhodamine to HUVECs, we were able to show the uptake of $\mathbf{1 b}$ but we failed to detect any rhodamine signal (ESI, Fig. S13 $\dagger$ ). Thus, 1 b seems to disassociate from the CDV upon entering the cells. The CDV might fuse with the plasma membrane and laterally diffuse within the membrane, thus diluting the signal below the detection limit. The CDV might also act as a carrier, enhancing the solubility of $\mathbf{1 b}$ in the aqueous medium. To further assess this, we tried to enhance uptake of $\mathbf{1 b}$ by increasing its solubility through the addition of $1 \%$ DMSO. Uptake efficiency of $\mathbf{1 b}$ in 1\% DMSO was, however, low and comparable to the uptake of $\mathbf{1 b}$ alone (Fig. 5).

To analyze the localization of the 1b@CDV within cells, HUVECs were incubated with preformed 1b@CDV $(1.25 \mu \mathrm{M}$ 1b complex and 3.75 $\mu \mathrm{M} \mathrm{CDV}$ ) diluted in medium and imaged after 5, 10, 20, 30 and $60 \mathrm{~min}$ (ESI, Fig. S14/15/16†). Initial experiments indicated an uptake of the complex via small vesicles and a subsequent localization to structures possessing a morphology reminiscent of mitochondria. To verify this localization and to identify the cellular compartments accessed by 1b, HUVECs were either transfected with a construct encoding the Mitochondrial Targeting Signal conjugated to mRFP (hereto referred as Mito-RFP) or the late endosomal marker Rab7-RFP. To label early endosomes, untransfected cells were incubated with $50 \mu \mathrm{g} \mathrm{mL}{ }^{-1}$ Transferrin-TexasRed for 5 min before starting the uptake of the complex. A partial colocalization with transferrin can be observed 5 min past addition of 1b@CDV (Fig. 4, ESI, Fig. S16†). After $10 \mathrm{~min}$ the Ir- 


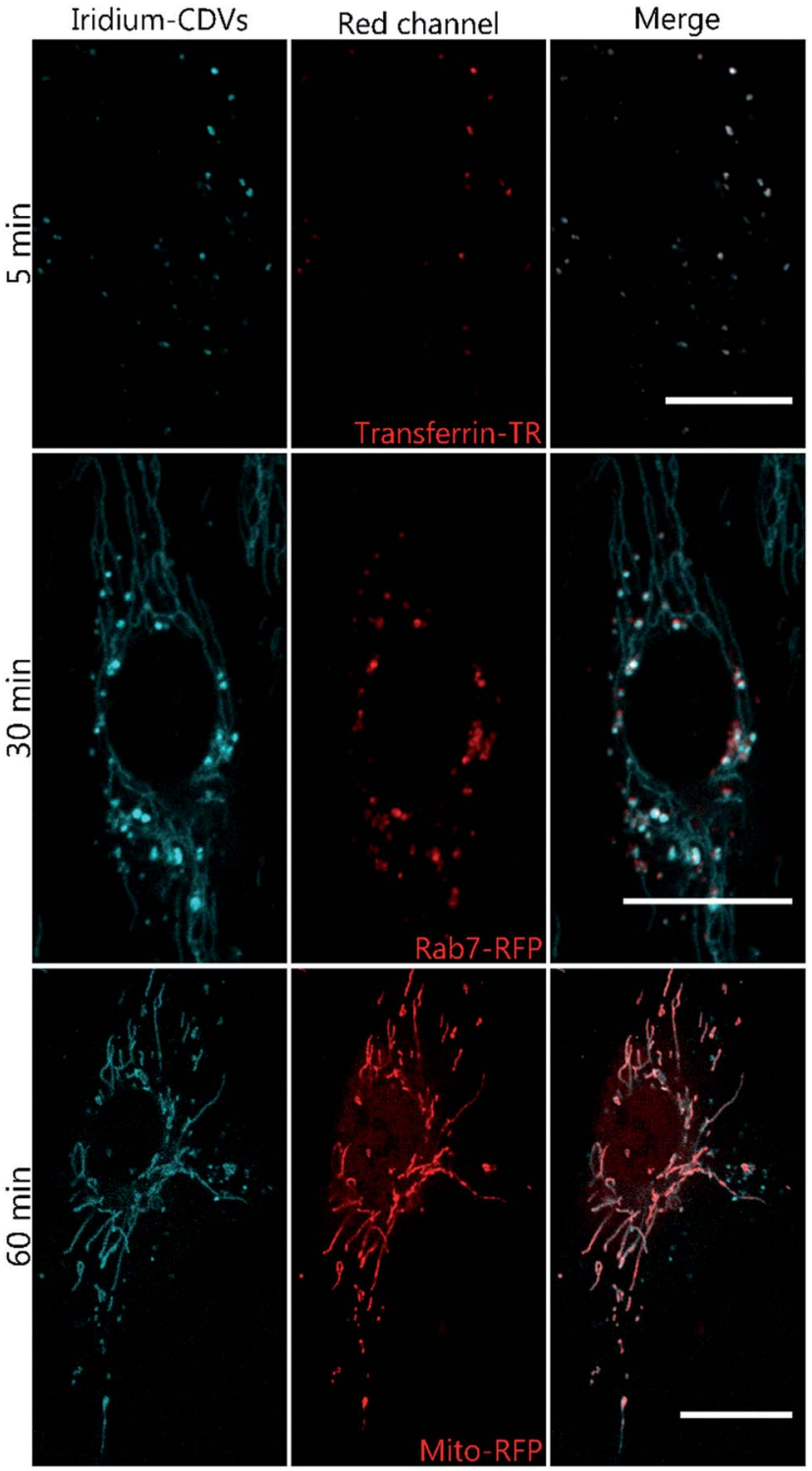

Fig. 4 Live cell confocal microscopy images of HUVEC after incubation with $1 \mathrm{~b}$-decorated CDV diluted in medium for $5 \mathrm{~min}, 30 \mathrm{~min}$ or $60 \mathrm{~min}$. The complex is shown in blue. Cells were either transfected with Rab7-RFP (middle panel) Mito-RFP (lower panel) or pre-treated with transferrin-TexasRed (upper panel) for $5 \mathrm{~min}$ to label early endosomes. Scale bar $20 \mu \mathrm{m}$.

complex starts to partially co-localize with Rab7 (ESI, Fig. S15†). This strongly indicates that $\mathbf{1 b} @ \mathrm{CDV}$ is taken up via an endocytic pathway, where it remains during endosomal maturation to late endosomes. At around $30 \mathrm{~min}$, co-localization between the Ir-complex and Rab7 is the strongest (Fig. 4). After $30 \mathrm{~min}$, the Ir-complex also starts to co-localize with mitochondria, indicative of a transfer from late endosomes to the mitochondria (Fig. 4, ESI, Fig. S14†).

The specific association of $\mathbf{1 b}$ with mitochondria that is even more evident at longer incubation times most likely is a consequence of both the high cationic charge and the lipophilicity of the Ir-complex, resulting in a preferred interaction with the mitochondria-specific lipid cardiolipin. The mitochondrial

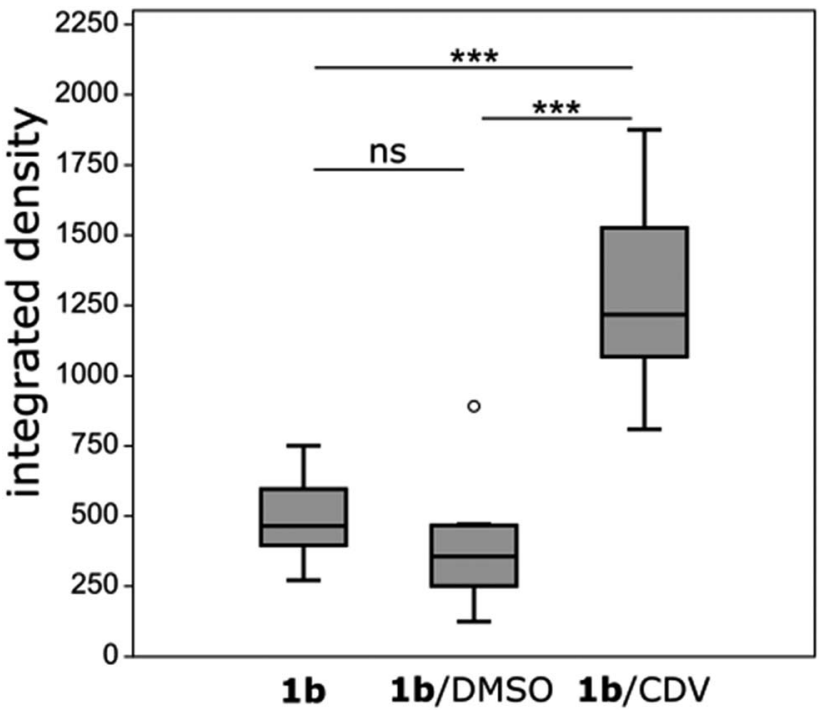

Fig. 5 Analysis of cell uptake of $1 \mathrm{~b}$ after $45 \mathrm{~min}$ of incubation with either $1.25 \mu \mathrm{M} 1 \mathrm{~b}, 1.25 \mu \mathrm{M} 1 \mathrm{~b}$ and $1 \%$ DMSO or $1.25 \mu \mathrm{M} 1 \mathrm{~b}$ and $3.75 \mu \mathrm{M}$ CDV. HUVECs were imaged ( $\lambda_{\text {exc }}=405 \mathrm{~nm}, \lambda_{\mathrm{em}}=410-556 \mathrm{~nm}$ ) and analyzed by thresholding the fluorescence signal and calculating the integrated signal density (mean fluorescence value $\times$ area). $n=10$ cells. ns $=$ non statistically significant, $* * *=$ statistical significance, $0=$ outlier data point. $1 \mathrm{~b} / 1 \mathrm{~b}+\mathrm{DMSO}: p=0.089 ; 1 \mathrm{~b} / 1 \mathrm{~b} \mathrm{aCDV}: p=0.0002$; $1 b+$ DMSO/1b aCDV: $p<0.0001$.

signal of $\mathbf{1 b}$ increases over the observed time period of $90 \mathrm{~min}$ and remains for at least $24 \mathrm{~h}$. It should be noted that $\operatorname{Ir}(\mathrm{III})$ complexes were already used to stain mitochondria in live cell imaging and it was shown that Ir-complexes possess several advantages to conventional Mitotracker reagents: ${ }^{46-50}$ due to their photostability, Ir-complexes can be used in long time imaging of cells and as opposed to Mitotracker, their localization to mitochondria is not dependent upon the mitochondrial membrane potential. MTT assays conducted in HeLa cells showed that the used complexes possess little cytotoxicity. In our work, more sensitive primary cells (HUVECs) were used and, importantly, no cytotoxic effects were observed. Thus, the immobilization of Ir-complexes on CDV result in a highly soluble and less toxic imaging agent that demonstrates improved uptake into cells. Due to their versatile intrinsic properties, the easy chemical modification and modular construction, CDV represent a diverse class of delivery systems in cellular approaches.

\section{Conclusions}

In summary, we have shown that two cationic Ir-complexes bearing adamantane anchoring units bind strongly to CDV giving rise to enhanced emissions that are shifted to higher energies compared to measurements in aqueous solution. This observation is attributed to a less polar and more viscous local environment near the CDV surface. Importantly, Ir-complexes immobilized on CDV can be readily internalized by cells where they eventually localize to mitochondria following transportation through the endocytic pathway. Ir-complexes 
without CDV were taken up with very little efficiency, demonstrating the capability of these vesicles as delivery vehicles. CDV decorated with luminescent Ir-complexes are therefore promising agents for bioimaging. We envisage that due to the modular self-assembly strategy, CDV can be developed into versatile platforms for theranostic applications.

\section{Conflicts of interest}

There are no conflicts to declare.

\section{Acknowledgements}

We are grateful for financial support by the Deutsche Forschungsgemeinschaft (DFG Ra 1732/7, SFB 858 and Ge 514/6) and Deutscher Akademischer Austauschdienst (DAAD). E. Z.C. acknowledges the University of St. Andrews and EPSRC (EP/ M02105X/1) for financial support.

\section{References}

1 Z. Liu, Z. Bian and C. Huang, in Molecular Organometallic Materials for Optics, ed. H. Bozec and V. Guerchais, Springer-Verlag, Berlin, Heidelberg, 2010, vol. 28, pp. 113142.

2 A. F. Henwood and E. Zysman-Colman, Chem. Commun., 2017, 53, 807.

3 E. Longhi and L. De Cola, in Iridium(III) in Optoelectronic and Photonics Applications, ed. E. Zysman-Colman, John Wiley \& Sons, Ltd, Chichester, UK, 2017, pp. 205-274.

4 Z.-G. Wu, Y.-M. Jing, G.-Z. Lu, J. Zhou, Y.-X. Zheng, L. Zhou, Y. Wang and Y. Pan, Sci. Rep., 2016, 6, 38478.

5 S. Kappaun, C. Slugovc and E. J. W. List, Int. J. Mol. Sci., 2008, 9, 1527.

6 D.-L. Ma, S. Lin, W. Wang, C. Yang and C.-H. Leung, Chem. Sci., 2017, 8, 878.

7 V. Guerchais and J.-L. Fillaut, Coord. Chem. Rev., 2011, 255, 2448.

8 K. K.-W. Lo, M.-W. Louie and K. Y. Zhang, Coord. Chem. Rev., 2010, 254, 2603.

9 K. K.-W. Lo, Acc. Chem. Res., 2015, 48, 2985.

10 Y. You and W. Nam, Chem. Soc. Rev., 2012, 41, 7061.

11 K. K.-W. Lo, K. H.-K. Tsang, K.-S. Sze, C.-K. Chung, T. K.-M. Lee, K. Y. Uhang, W.-K. Hui, C.-K. Li, J. S.-Y. Lau, D. C.-M. Ng and N. Zhu, Coord. Chem. Rev., 2007, 251, 2292.

12 J. Chan, S. C. Dodani and C. J. Chang, Nat. Chem., 2012, 4, 973.

13 Q. Zhao, M. Yu, L. Shi, S. Liu, C. Li, M. Shi, Z. Zhou, C. Huang and F. Li, Organometallics, 2010, 29, 1085.

14 K. K.-S. Tso and K. K.-W. Lo, in Iridium(III) in Optoelectronic and Photonics Applications, ed. E. Zysman-Colman, John Wiley \& Sons, Ltd, Chichester, UK, 2017, vol. 1, pp. 415-477.

15 L. C. C. Lee, J. C. W. Lau, H. W. Liu and K. K. W. Lo, Angew. Chem., Int. Ed., 2016, 55, 1046.

16 C. Li, M. Yu, Y. Sun, Y. Wu, C. Huang and F. Li, J. Am. Chem. Soc., 2011, 133, 11231.
17 J. Wang, J. Xue, Z. Yan, S. Zhang, J. Qiao and X. Zhang, Angew. Chem., Int. Ed., 2017, 56, 14928.

18 S. P.-Y. Li, H.-W. Liu, K. Y. Zhang and K. K.-W. Lo, Chem.Eur. J., 2010, 16, 8329.

19 H. Yang, L. Li, L. Wan, Z. Zhou and S. Yang, Inorg. Chem. Commun., 2010, 13, 1387.

20 S. P. Li, C. T. Lau, M. Louie, Y. Lam, S. H. Cheng and K. K. Lo, Biomaterials, 2013, 34, 7519.

21 Y. Li, C. Tan, W. Zhang, L. He, L. Ji and Z. Mao, Biomaterials, 2015, 39, 95.

22 E. M. M. Del Valle, Process Biochem., 2004, 39, 1033-1046.

23 G. Crini, Chem. Rev., 2014, 114, 10940.

24 M. V. Rekharsky and Y. Inoue, Chem. Rev., 1998, 98, 1875.

25 M. T. M. Rood, S. J. Spa, M. M. Welling, J. B. ten Hove, D. M. van Willigen, T. Buckle, A. H. Velders and F. W. B. van Leeuwen, Sci. Rep., 2017, 7, 39908.

26 S. M. N. Simões, A. Rey-Rico, A. Concheiro and C. AlvarezLorenzo, Chem. Commun., 2015, 51, 6275.

27 P. Falvey, C. W. Lim, R. Darcy, T. Revermann, U. Karst, M. Giesbers, A. T. M. Marcelis, A. Lazar, A. W. Coleman, D. N. Reinhoudt and B. J. Ravoo, Chem.-Eur. J., 2005, 11, 1171.

28 J. Voskuhl and B. J. Ravoo, Chem. Soc. Rev., 2009, 38, 495.

29 J. Voskuhl, M. C. A. Stuart and B. J. Ravoo, Chem.-Eur. J., 2010, 16, 2790.

30 F. Schibilla, J. Voskuhl, N. A. Fokina, J. E. P. Dahl, P. R. Schreiner and B. J. Ravoo, Chem.-Eur. J., 2017, 23, 16059.

31 W. C. De Vries, D. Grill, M. Tesch, A. Ricker, N. Harald, J. Klingauf, A. Studer, V. Gerke and B. J. Ravoo, Angew. Chem., Int. Ed., 2017, 56, 9603.

32 J. M. Haider, R. M. Williams, L. De Cola and Z. Pikramenou, Angew. Chem., Int. Ed., 2003, 42, 1830.

33 F. C. M. Leung, V. K. M. Au, H. O. Song and V. W. W. Yam, Chem.-Eur. J., 2015, 21, 16448.

34 N. Mourtzis, P. C. Carballada, M. Felici, R. J. M. Nolte, R. M. Williams, L. de Cola and M. C. Feiters, Phys. Chem. Chem. Phys., 2011, 13, 7903.

35 P. Contreras Carballada, N. Mourtzis, M. Felici, S. Bonnet, R. J. M. Nolte, R. M. Williams, L. De Cola and M. C. Feiters, Eur. J. Org. Chem., 2012, 6729.

36 S. Ladouceur and E. Zysman-Colman, Eur. J. Inorg. Chem., 2013, 2985.

37 A. Singh, K. Teegardin, M. Kelly, K. S. Prasad, S. Krishnan and J. D. Weaver, J. Organomet. Chem., 2015, 776, 51-59.

38 K. Suzuki, A. Kobayashi, S. Kaneko, K. Takehira, T. Yoshihara, H. Ishida, Y. Shiina, S. Oishi and S. Tobita, Phys. Chem. Chem. Phys., 2009, 11, 9850.

39 W. H. Melhuish, J. Phys. Chem., 1961, 65, 229-235.

$40 \mathrm{~S}$. Ladouceur, D. Fortin and E. Zysman-Colman, Inorg. Chem., 2011, 50, 11514.

41 F. Lafolet, S. Welter, Z. Popović and L. De Cola, J. Mater. Chem., 2005, 15, 2820.

42 L. R. Alrawashdeh, M. P. Cronin, C. E. Woodward, A. I. Day, L. Wallace, E. Woodward, A. I. Day and L. Wallace, Inorg. Chem., 2016, 55, 6759. 
43 F. Scarpelli, A. Ionescu, L. Ricciardi, P. Plastina, I. Aiello, M. La Deda, A. Crispini, M. Ghedini and N. Godbert, Dalton Trans., 2016, 45, 17264.

44 T. S.-M. Tang, K.-K. Leung, M.-W. Louie, H.-W. Liu, S. H. Cheng and K. K.-W. Lo, Dalton Trans., 2015, 44, 4945.

45 W. C. Cromwell, K. Byström and M. R. Eftink, J. Phys. Chem., 1985, 89, 326.

46 Q. Zhang, R. Cao, H. Fei and M. Zhou, Dalton Trans., 2014, 43, 16872 .
47 K. Qiu, H. Huang, B. Liu, Y. Liu, P. Zhang, Y. Chen, L. Ji and H. Chao, J. Mater. Chem. B, 2015, 3, 6690.

48 Y. Chen, L. Qiao, B. Yu, G. Li, C. Liu, L. Ji and H. Chao, Chem. Commun., 2013, 49, 11095.

49 L. K. McKenzie, I. V. Sazanovich, E. Baggaley, M. Bonneau, V. Guerchais, J. A. G. Williams, J. A. Weinstein and H. E. Bryant, Chem.-Eur. J., 2017, 23, 234.

50 C. Jin, J. Liu, Y. Chen, L. Zeng, R. Guan, C. Ouyang, L. Ji and H. Chao, Chem.-Eur. J., 2015, 21, 12000. 